\title{
REFLEXÕES SOBRE UM DESENCAIXE NA EDUCAÇÃO BRASILEIRA E O EVENTUAL IMPASSE ENTRE O DOCENTRISMO E O DISCENTRISMO
}

\author{
Alexandre Marucci BASTOS ${ }^{1}$ \\ Maria Teresa Miceli KERBAUY ${ }^{2}$
}

RESUMO: As instituições desencaixadas dilatam amplamente o escopo do distanciamento tempo-espaço, já que a separação entre tais elementos é crucial para o extremo dinamismo da modernidade; sendo a condição principal do processo de desencaixe, pelo qual se favorece o deslocamento das relações sociais de contextos locais de interação e sua reestruturação por meio de extensões indefinidas de tempo e espaço. Para tanto, há dois tipos de mecanismos de desencaixe intrinsecamente envolvidos no desenvolvimento das instituições sociais modernas: "fichas simbólicas" e "sistemas peritos". Mecanismos estes que dependem de confiança. Nesse contexto, o presente trabalho coloca o Ciclo de Vida Profissional do Professor (CVPP) sob a perspectiva do sistema perito; e a estabilidade empregatícia do funcionalismo público na ótica da ficha simbólica - mais especificamente do professor da rede pública de ensino no Brasil. Na pretensão de propor algumas reflexões sobre o que seria um desencaixe na Educação Brasileira e no que um eventual impasse entre o "docentrismo" e o "discentrismo" afetaria esse processo se assim ele se fizer necessário ou desejado frente à modernidade.

PALAVRAS-CHAVE: Desencaixe. Sistema perito. Ficha simbólica. Ciclo de Vida Profissional do Professor - CVPP. Estabilidade empregatícia.

\section{INTRODUÇÃO}

Partindo do pressuposto de que não é possível dissociar a dinâmica educacional dos elementos tempo e espaço, este texto discutirá sobre essa eventual correlação com base nos postulados do sociólogo britânico Anthony Giddens. Teórico contemporâneo, cujo interesse centra-se em reformular a teoria social e reexaminar a compreensão do desenvolvimento e da modernidade, alegando que, para compreender adequadamente a natureza da modernidade, temos de dar conta do extremo dinamismo e do escopo globalizante das instituições modernas e explicar a natureza de suas descontinuidades em relação às culturas tradicionais. Nessa abordagem, o autor assevera que é necessário distinguir vários conjuntos de elementos que assim as caracterizem, cada um dos quais é

${ }^{1}$ Doutorando em Educação Escolar. UNESP - Universidade Estadual Paulista. Faculdade de Ciências e Letras - Pós-graduação em Educação Escolar. Araraquara - SP - Brasil. 14800-901 amarucci@uol.com.br

${ }_{2}^{2}$ UNESP - Universidade Estadual Paulista. Faculdade de Ciências e Letras - Departamento de Antropologia, Política e Filosofia. Araraquara - SP - Brasil. 14800-901 - kerbauy@travelnet.com.br 
relevante tanto para o caráter dinâmico como para o caráter "de alcance mundial" das instituições modernas (GIDDENS, 1991, p.21).

O dinamismo da modernidade, segundo o mesmo autor, deriva da separação do tempo e do espaço e de sua recombinação em formas que permitem o "zoneamento" tempo-espacial preciso da vida social; bem como do desencaixe dos sistemas sociais (um fenômeno intimamente vinculado aos fatores envolvidos na separação tempoespaço); e da ordenação e reordenação reflexiva das relações sociais à luz das contínuas entradas (inputs) de conhecimento, as quais afetariam as ações de indivíduos e grupos, incluindo um exame inicial da natureza da confiança, a começar pela ordenação do tempo e do espaço (GIDDENS, 1991).

Para Giddens (1991), a separação entre tempo e espaço é crucial para o extremo dinamismo da modernidade, pois se faz como a condição principal do processo de desencaixe. Dessa forma, as instituições desencaixadas dilatam amplamente o escopo do distanciamento tempo-espaço e, para ter este efeito, dependem da coordenação por intermédio do tempo e do espaço. Esse fenômeno serve para abrir múltiplas possibilidades de mudanças, liberando das restrições dos hábitos e das práticas locais.

Concomitantemente, ao se separar tempo e espaço, proporcionam-se os mecanismos de engrenagem para aquele traço distintivo do que seria a vida social moderna: a organização racionalizada. No entanto, segundo as colocações de Giddens, as organizações (inclusive os estados modernos) podem às vezes ter a qualidade um tanto quanto estática, inercial, que Max Weber associava à burocracia; mas, mais comumente, elas têm um dinamismo que contrasta agudamente com as ordens prémodernas. Não obstante, Giddens destaca o fato de as organizações modernas serem capazes de conectar o local e o global de forma que seriam impensáveis em sociedades mais tradicionais, e, assim fazendo, afetam rotineiramente o status quo estabelecido; consectário, a vida de milhões de pessoas (GIDDENS, 1991).

\section{O DESENCAIXE E A DINÂMICA EDUCACIONAL (PÚBLICA) BRASILEIRA DIANTE À MODERNIDADE}

Por desencaixe, conceitual e especificamente, Giddens (1991, p.24) se refere ao "deslocamento" das relações sociais de contextos locais de interação e sua reestruturação por meio de extensões indefinidas de tempo-espaço. Para esse autor, os sociólogos têm discutido com frequência a transição do mundo tradicional ao mundo 
moderno em termos de conceitos de "diferenciação" ou "especialização funcional". Entretanto, para Giddens, as noções desses conceitos não são muito adequadas para lidar com o fenômeno da vinculação do tempo e do espaço pelos sistemas sociais, sendo que, para ele, a imagem evocada pelo desencaixe é mais apta a capturar os alinhamentos em mudança de tempo e espaço, fundamentais para a mudança social em geral e para a natureza da modernidade em particular (GIDDENS, 1991).

Giddens (1991) distingue dois tipos de mecanismos de desencaixe intrinsecamente envolvidos no desenvolvimento das instituições sociais modernas. $\mathrm{O}$ primeiro deles o autor denomina de criação de "fichas simbólicas"; o segundo, de estabelecimento de "sistemas peritos". Para o primeiro, Giddens utiliza o dinheiro como exemplo enfático, não obstante destacando a existência de vários tipos de fichas simbólicas, tais como aqueles representados pelos meios de legitimação política. Para o segundo, sistemas peritos, o autor se refere a sistemas de excelência técnica ou competência profissional que organizam grandes áreas dos ambientes material e social em que vivemos hoje.

Todos os mecanismos de desencaixe - tanto as fichas simbólicas como os sistemas peritos - dependem da confiança. A confiança revestida de capacidades não individuais de ideias está, destarte, envolvida de uma maneira fundamental com as instituições da modernidade (GIDDENS, 1991). Dessa forma, pela reflexão proposta pelo presente estudo, resta saber se existe a consciência - concomitantemente à vontade e condições - para, caso assim se julgue necessário, ajustar a realidade educacional brasileira ao que se entenderia por modernidade, de modo a propiciar um eventual desencaixe nesse sentido. $\mathrm{O}$ que, para tanto, e indiferente a eventuais implicações paradigmáticas, levaria em conta o extremo dinamismo advindo do escopo globalizante das instituições modernas, na pretensão de explicar a natureza de suas descontinuidades em relação às culturas tradicionais.

Para o contexto trazido à luz da discussão, subsidiado pelos postulados de Giddens, este texto busca colocar o Ciclo de Vida Profissional do Professor (CVPP) sob a perspectiva do sistema perito; e a estabilidade empregatícia do funcionalismo público na perspectiva da ficha simbólica - mais especificamente do professor da rede pública de ensino. Nesse caso, mais como elemento de legitimação política do que um meio de intercâmbio que possa ser "circulado", sobretudo quanto à convergência da ensejada estabilidade à confiança revestida pelo manto da presunção de que outrem a reconheçam e honrem o seu valor. 


\section{O CVPP E A ESTABILIDADE EMPREGATÍCIA DO FUNCIONALISMO PÚBLICO}

Tratar do tema "Ciclo de Vida Profissional do Professor" (CVPP) evoca a obra homônima de Michael Huberman (1992). A princípio, esse autor destaca o fato de que, com exceção dos estudos de Peterson de 1964, publicado em Nova Iorque (EUA) ${ }^{3}$, até a década de 1960 verifica-se uma quase ausência de pesquisas sobre a "carreira" do professor; até então, a grande maioria dos estudos em torno da docência havia incidido apenas no período de formação inicial e no princípio da carreira (HUBERMAN, 1992).

Convergindo à essência do CVPP de Michael Huberman, têm-se os estudos de Carlos Marcelo Garcia (1991 e 1998), catedrático da Universidade de Sevilla (Espanha). No entanto, nas suas duas obras apreciadas, há amplitudes distintas: na de 1991, a fase incipiente da carreira do professor, inclusive quanto à sua entrada nesse trajeto profissional, é enfatizada. Especificamente em seu Capítulo 1 (base da discussão deste tópico), Marcelo recorre a vários autores para fundamentar suas proposições, com destaque para Burke (1988), Veenman (1984), e Fuller e Brown (1975). Todavia, Marcelo ainda não contextualiza com os postulados do CVPP de Michael Huberman em toda essa sua publicação de 1991, pois só em 1992 Huberman os publicaria.

Já na sua publicação de 1998, Marcelo até promove uma retomada revisional teórica de Burke (BURKE et al., 1984, não mais de 1988) e Veenman (1984), porém se lança a fazer com que os postulados de Huberman, relativos ao ciclo vital dos professores, ganhem certa relevância ${ }^{4}$. Nesse novo contexto, Marcelo avança além dos momentos iniciais da carreira do professor; discutindo de forma mais abrangente as pesquisas desde a formação inicial de professores e sua respectiva iniciação na atividade profissional de docência, até seu desenvolvimento profissional (em um breve contraponto entre iniciantes e experientes).

Se os estudos centravam-se a priori nos professores em formação, pouco a pouco foi surgindo considerável literatura de pesquisa a respeito dos professores principiantes e daqueles em exercício. Dessa forma, permite-se dizer que, em linhas gerais, o CVPP consiste em fases (etapas) compreendidas desde a iniciação em Educação; cujo período de tempo abrangeria os primeiros anos de ensino, em que os

\footnotetext{
${ }^{3}$ Peterson (1964). Reedição da obra de Sara Delamont: Readings on interaction in the classroom: contemporary sociology of the school. New York: Methuen, 1984. 350 p.

${ }^{4}$ Neste texto, a obra de Huberman apreciada é a versão traduzida, de 1992. Enquanto Marcelo, a de 1989.
} 
professores têm de fazer a transição de estudantes a professores (BURKE, 1984 apud MARCELO, 1991, p.9), até a aposentadoria.

No entanto, em meio a esse trajeto, há de se registrar, mesmo que em síntese, as contextualizações envolvendo as etapas do CVPP. Tanto dos postulados de Huberman (1992), como os desdobramentos dessas contextualizações levadas a efeito por Marcelo (1991 e 1998), inclusive quanto aos "estágios evolutivos das preocupações dos professores" no processo de aprender a ensinar ao longo de sua carreira (FULLER; BROWN, 1975 apud MARCELO, 1991). Os principais pontos especulativos que constituem o CVPP são sintetizados no iconográfico da Figura 1, desenvolvido a partir das obras de Huberman (1992) e de Marcelo (1991 e 1998).

Figura 1 - Iconográfico do ciclo vital dos professores e as etapas evolutivas de suas preocupações no processo de aprender a ensinar

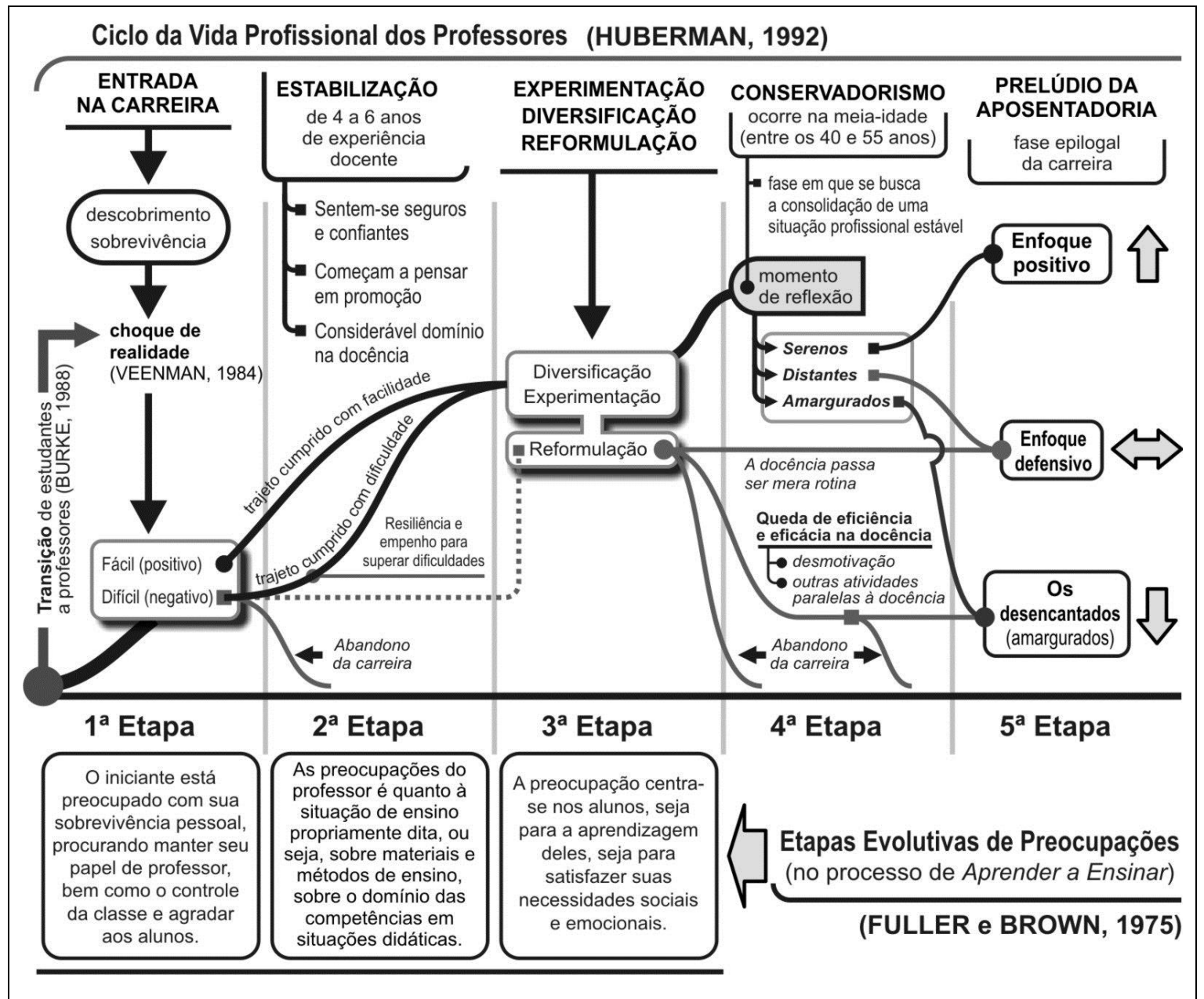

Fonte: Elaboração baseada em Huberman (1992), Burke (1988), Veenman (1984), Fuller e Brown (1975) apud Marcelo (1991, 1998). 
Conforme sugere Huberman ao longo de sua obra, as fases ou etapas do CVPP não são estáticas e tampouco podem ser aplicadas indistintamente a todos, pois não é possível integrar pessoas em um grupo, simplesmente pelo tempo de experiência ou pela idade, sem considerar seus antecedentes, seu percurso e sua história pessoal. Assim, os ciclos apontados por Huberman não são lineares, previsíveis ou explicáveis para todos os professores, pois cada um vive sua carreira de acordo com sua história, suas oportunidades, seus investimentos.

Considerando, porquanto, que os elementos intrínsecos do indivíduo se revestiriam pela inequívoca relevância no CVPP, cabe pertinência considerar também a questão geopolítica em tal contexto. Nesse sentido, independentemente da delimitação geográfica pela qual se desenvolveu a pesquisa de Huberman, há de se refletir sobre como seus postulados se acoplam à realidade brasileira; outrossim, quando o CVPP passa a ser compreendido como sistema perito, principalmente a partir do momento que se traz à luz da discussão os aspectos relativos à formação dos professores e, sobretudo, ao que se espera de todo esse processo; seja ele inicial ou ao longo da carreira docente no âmbito da Educação Básica pública no Brasil.

Eis aqui, então, parte da analogia proposta por este texto, pela qual se delineia os supostos elementos tempo e espaço (inerentes aos postulados de Giddens já comentados), a fim de discutir a questão do desencaixe mais adiante. Onde o CVPP remeteria ao tempo, e o espaço estando relacionado ao Brasil e suas politicas públicas educacionais, com ênfase nos programas de formação de professores consoante ao sistema perito ensejado por Giddens.

Por tal abordagem, tornam-se oportunos os estudos de Gatti, Barreto e André (2011), pelos quais é possível uma panorâmica das políticas docentes no Brasil. Nesse trabalho, as autoras promovem uma apresentação de programas nacionais voltados à formação de professores, não obstante as implicações do contexto legiferante imposto pelo Governo Federal nesse sentido. Tanto que, em menos de uma década, o Ministério da Educação (MEC) montou um grande aparato institucional, com a finalidade de organizar, em regime de colaboração entre a União, os Estados, o Distrito Federal e os Municípios, a formação inicial e continuada dos profissionais do magistério para as redes públicas da Educação Básica; cuja coordenação ficou sob a responsabilidade da Coordenadoria de Aperfeiçoamento de Pessoal de Nível Superior (Capes) e pelo seu Conselho Técnico da Educação Básica. 
Esse compartilhamento colaborativo veio a originar o Plano Nacional de Formação dos Professores da Educação Básica - PARFOR, o qual se configura, portanto, como o resultado de um conjunto de ações do MEC; cujas articulações se dão por meio dos Fóruns Estaduais Permanentes de Apoio à Formação Docente, em colaboração com as Secretarias de Educação dos Estados e Municípios e das Instituições Públicas de Educação Superior (IPES), neles sediadas (GATTI; BARRETO; ANDRÉ, 2011, p.252-253).

Paralelamente, conforme coloca Gatti, Barreto e André (2011, p.253), passou a ser fortalecida a atuação do Instituto Nacional de Estudos e Pesquisas Educacionais Anísio Teixeira (Inep) como agência federal de acompanhamento e avaliação das políticas de currículo da Educação Básica e Superior; bem como da formação docente e, em última análise, do próprio trabalho desenvolvido por estes profissionais no contexto educacional pretendido. Pelas explanações na obra dessas mesmas autoras, percebe-se o esforço governamental em dar relevantes contribuições ao exercício da docência na rede pública, o que em tese enrijeceria o respectivo sistema perito sublinhado.

Entretanto, pode-se dizer que tal contexto estaria ainda sendo supostamente apreciado por uma perspectiva bidimensional. Para potencializar a análise inserir-seiam, teoricamente, mais duas dimensões: a que evoca os aspectos vocacionais e a que compreende a estabilidade empregatícia na carreira pública. Quanto à discussão da primeira, será contextualizada nas considerações finais. Já a segunda se discute a seguir.

A estabilidade no serviço público no Brasil é um direito adquirido para quem a conquistou, e ponto final. Que, grosso modo, só será colocado em xeque em circunstâncias extremadas. Em outras palavras se, em tese, o adquirente explicitamente "forjar" sobremaneira sua própria vulnerabilidade. Assim, a configuração da estabilidade na perspectiva da ficha simbólica se daria mais como elemento de legitimação política do que um meio de intercâmbio que possa ser "circulado". Ademais, o ensejado estatuto da estabilidade convergiria à confiança revestida pelo manto da presunção de que outrem o reconheça, bem como honrem o seu valor. Nessa abordagem, a estabilidade estaria também relacionada ao elemento "espaço" consoante ao âmbito do serviço público, bem como ao do ambiente educacional público brasileiro. Já ao elemento “tempo", em razão dos próprios aspectos tempestivos. Seja para adquirila, seja, consectário, para desfrutá-la. 


\section{CONSIDERAÇÕES FINAIS: REFLEXÕES SOBRE UM DESENCAIXE NA EDUCAÇÃO BRASILEIRA E O EVENTUAL IMPASSE ENTRE O "DOCENTRISMO" E O "DISCENTRISMO"}

Ao colocar à luz da discussão o ciclo de vida profissional do professor (CVPP) - como um sistema perito -, sob o viés da estabilidade empregatícia docente no âmbito público - como ficha simbólica -, poderia levantar uma hipótese na qual esse contexto poderia apontar para um descompasso da confiabilidade mútua que envolveria tais questões.

Como já colocado, a estabilidade no serviço público, segundo os preceitos legais brasileiros vigentes, é um direito adquirido para quem a conquistou, e ponto final. Ou seja, um estatuto na forma de uma ficha simbólica que já assegurou a confiança de que outrem (a sociedade como um todo) a reconheça e a legitime. O CVPP por sua vez, pela perspectiva do sistema perito, também deveria, em tese, ensejar a confiança gerada pelos pressupostos de um sistema equivalente de excelência técnica ou competência profissional que organizam grandes áreas dos ambientes material e social em que vivemos hoje, no caso a Educação.

Mediante o exposto, e em que pese o esforço do Estado em promover doutrinas que buscaram, ou ainda buscam, dar a devida relevância à eficácia e eficiência no serviço público, o fato é que, se por um lado ainda não seria possível afirmar com veemência que houve alterações práticas substanciais que refletissem diretamente na melhoria da qualidade da prestação dos serviços oferecidos à sociedade; por outro, há condições para reconhecer que o Estado providenciou determinadas ações e rubricas orçamentárias para incentivar programas para a qualificação profissional de alguns estratos do funcionalismo público nas mais diversas esferas de governo (Federal Estadual - Municipal).

Entre as ações e investimentos visando melhorias na qualificação profissional nos quadros do serviço público, destacaram-se neste texto - segundo os estudos providenciados por Gatti, Barreto e André (2011) - aqueles que instituíram a Política Nacional de Formação de Profissionais do Magistério da Educação Básica; com a finalidade de organizar, em regime de colaboração entre a União, os Estados, o Distrito Federal e os Municípios, a formação inicial e continuada dos profissionais do magistério para as redes públicas da Educação Básica.

Nessa definição de responsabilidades quanto ao processo contínuo que se inicia na formação inicial - e que, em tese, prossegue ao longo da vida profissional -, a 
política criada pelo MEC também envolve as Instituições Públicas de Educação Superior (IPESs) na formação em serviço dos professores da Educação Básica; bem como as Secretarias Estaduais e Municipais de Educação a que pertencem os docentes. Em regime de colaboração entre os entes federados, tal política se propõe a contribuir para a construção de uma prática docente qualificada e para a afirmação da identidade e da profissionalidade dos docentes.

Por tal abordagem, pode-se dizer que, da mesma forma que o alicerce se faz fundamental em uma edificação, a formação inicial assim poderá ser na solidez da carreira docente e, por conseguinte, no que isso implicaria na essência de um efetivo sistema perito. Nessa analogia, pode-se dizer que a consistência do alicerce nesse caso estará também em função da compatibilidade vocacional do indivíduo, bem como seu alinhamento e resiliência frente às realidades em que vive ou até às que fatalmente ele se deparará.

É talvez nesse aspecto que possa estar um contexto contingencial merecedor de especial atenção, pois, segundo o panorama das políticas docentes traçado por Gatti, Barreto e André (2011), a percepção leva a crer que no cenário atual muitas ações de formação docente dão indícios de serem apenas reativas. As essências proativas e preditivas sugerem sequer existirem. Um cenário que daria margens para considerar a possibilidade de tais ações se tratarem mais de estratégias visando ajustar uma realidade inadequada para, em suposto esquivamento, abastecer estatísticas inócuas que estariam dando uma satisfação política, tipo “o Estado está fazendo sua parte”, revalidando o famoso aforismo lusitano: "a culpa morre solteira". Seria como pintar telhados e paredes, quando na verdade haveria a necessidade de se preocupar desde os alicerces.

Ademais, uma iniciativa que aja longe da percepção comum e não mostre resultados imediatistas teria menor impacto mediático. Além do que, haveria a necessidade de o Nível Federal considerar: (1) que a centralização não seria o melhor caminho; e (2) que um fluxo predominante nas definições de diretrizes, no sentido de cima para baixo (top-down), não favorece e tampouco garante uma melhoria contínua operacional, sobretudo quando se anota a ausência de condições favoráveis para um feedback (resposta) eficaz e em tempo compatível para tal propósito - algo propiciado por meio de um percurso inverso, no sentido de baixo para cima (bottom-up).

Por esse prisma analítico há indícios de que, já na entrada da carreira, os professores iniciantes correm o risco de assumirem, até involuntariamente, um passivo formativo a eles implicitamente debitado, o qual infelizmente deverá ser saldado de 
alguma forma por eles - ou por alguém - ao longo do trajeto de seu próprio ciclo de vida profissional. Tal cenário ainda poderia ser agravado se consideramos os aspectos complementares e eletivos a seguir:

$1^{\circ}$. Caso a docência não seja de fato a vocação do indivíduo, e que a escolha por essa carreira foi motivada, sobretudo, pela busca de sua sobrevivência. Uma fonte pecuniária gerada por algo configurado como um "escaler" profissional.

$2^{\circ}$. Quando o indivíduo é refratário a iniciativas de aprimoramento docente, oferecidas a ele. Pior ainda, nesse caso, se tratando daquele que se lançou à docência sem o mínimo de vocação ou identidade profissional.

$3^{\circ}$. Quando o indivíduo chega a aderir a algumas iniciativas de aprimoramento docente, porém apenas quando estas representem algum tipo de vantagem pecuniária pessoal.

$4^{\circ}$. Quando o professor até está propenso a se aprimorar, mas tanto a entidade como o ambiente, no qual ele está vinculado, não oferece condições propícias de aprimoramento e tampouco o estimula para tanto.

$5^{\circ}$. Quando além do que foi contextualizado nos itens anteriores, a função docente é revestida pelo manto da estabilidade empregatícia, consoante ao exercício da respectiva função na rede pública de ensino, e o indivíduo não vê mais razão alguma para se aprimorar.

Os aspectos levantados acima sugerem algumas indagações em relação ao sistema perito:

- O sujeito tem realmente vocação ou identidade profissional para a docência?... Ou ele decidiu por essa carreira apenas pelo fato de ela representar sua "tábua de salvação", como a última alternativa de sobrevivência ou até mesmo para lhe proporcionar certo posicionamento social e profissional? 
- O docente reconhece a importância de seu contínuo aprimoramento profissional, independentemente de receber quaisquer vantagens pecuniárias por isso?

- Quais os anteparos proativos institucionais que eventualmente sustentariam as ações de aprimoramento docente?

- Há como aprimorar um professor que vilipendia - ou até mesmo renega em tergiversação - quaisquer iniciativas nesse sentido, mas que já conquistou juridicamente sua estabilidade empregatícia?

- O que levaria um indivíduo sem vocação docente, amargurado e, ainda por cima, refratário a quaisquer iniciativas de aprimoramento em sua contínua formação, a abandonar a carreira após ter conquistado sua estabilidade empregatícia?

- Qual o nível de "contaminação" - no âmbito escolar - provocada pela postura dos professores (sobretudo os estáveis) refratários às iniciativas de aprimoramento contínuo e daqueles que adentraram na carreira sem uma vocação docente compatível à missão educacional?

Muitos outros questionamentos poderiam ser levados a termo pelo contexto trazido à luz da discussão. Contudo, já há elementos suficientes para considerar eventuais problemas na carreira docente por conta de situações contidas ainda nos alicerces da mesma; os quais poderiam causar efeitos colaterais subsequentes, mas que ainda não foram devidamente tratados de forma a mitigá-los. Ou seja, é possível que esteja havendo certo predomínio de esforços focando nas consequências, quando na verdade deveriam se atentar às causas. Algo que remete a leitura para uma oportuna proatividade num contexto de causa e efeito.

Em que pese alguns estudos tratarem especificamente dos aspectos envolvendo a articulação da teoria com a prática docente - sobretudo quando da entrada do iniciante em seu Ciclo de Vida Profissional do Professor (CVPP) -, pode-se dizer que qualquer carreira profissional estará com mais chances de êxito se quem a escolheu tiver vocação ao que se propôs fazer; e, melhor ainda, se vier fazer aquilo que realmente gosta.

Oportuniza-se, assim, uma reflexão sobre o quanto a vocação e a estabilidade empregatícia possam estar afetando um eventual desencaixe na dinâmica educacional brasileira, ou até mesmo o impedindo. Um enredo definido a partir da inferência sobre a 
constituição da carreira do professor, bem como as implicações de tais questões ao que se espera de um inequívoco sistema perito na Educação e a respectiva confiança que estaria naturalmente depositada na docência. Seja desde a ensejada sedimentação teórica, já a partir de sua formação inicial, consoante ao seu respectivo alicerce profissional, ou até mesmo nos resultados práticos e efetivos esperados por ações posteriores de caráter reativo ou corretivo.

Guarnieri (2005) fornece, ao longo de seu estudo, elementos para realçar a importância de se preocupar com a construção da função docente e na subsequente consolidação do processo de se tornar um professor; sobretudo quando tal construção decorra da capacidade do iniciante em articular seu conhecimento teórico-acadêmico com a prática. Algo, por sua vez, diretamente associado ao universo escolar. Em síntese, pelo contexto interposto pela autora, passa a ser relevante considerar o quanto se faz fundamental preparar adequadamente o professor iniciante já na entrada no percurso do CVPP, caso contrário os riscos para uma carreira tumultuada e até mesmo malsucedida poderão ser maiores. Nesse sentido, a mesma autora evidencia, em seu texto, a necessidade de ações tanto nos cursos de formação como na intervenção no âmbito da educação continuada que visem uma preparação adequada dos professores para a mencionada articulação: entre a teoria e prática.

Apesar da inegável relevância das políticas de formação docente no Brasil, elas seriam supostamente mais profícuas se o público-alvo consistisse de fato em professores que se identificam com a docência; e que, além da compatibilidade vocacional, tais sujeitos apresentem disposição em desenvolver uma condizente capacidade cognitiva; bem como haja uma adequada intensidade sinérgica a esse propósito, por parte das instituições com as quais os professores estejam vinculados, inclusive da própria comunidade local atendida.

Se considerarmos a fase da formação inicial e a entrada do professor no CVPP como a essência dos alicerces de sua carreira; e que, agindo nesta etapa de forma preditiva e proativa, minimizaria eventuais contingências operacionais futuras, cabe pertinência a lógica aplicada no esquema proposto pelo iconográfico da Figura 2; pelo qual se propõe um fluxograma de modo a detectar onde residiriam alguns aspectos do CVPP e da estabilidade empregatícia, cujos desdobramentos poderiam afetar um pretenso desencaixe na dinâmica educacional brasileira, numa eventual necessidade (e desejo) de se ajustar à modernidade. 
Figura 2 - As possíveis variantes contidas no trajeto básico da carreira do professor em seu ciclo de vida profissional

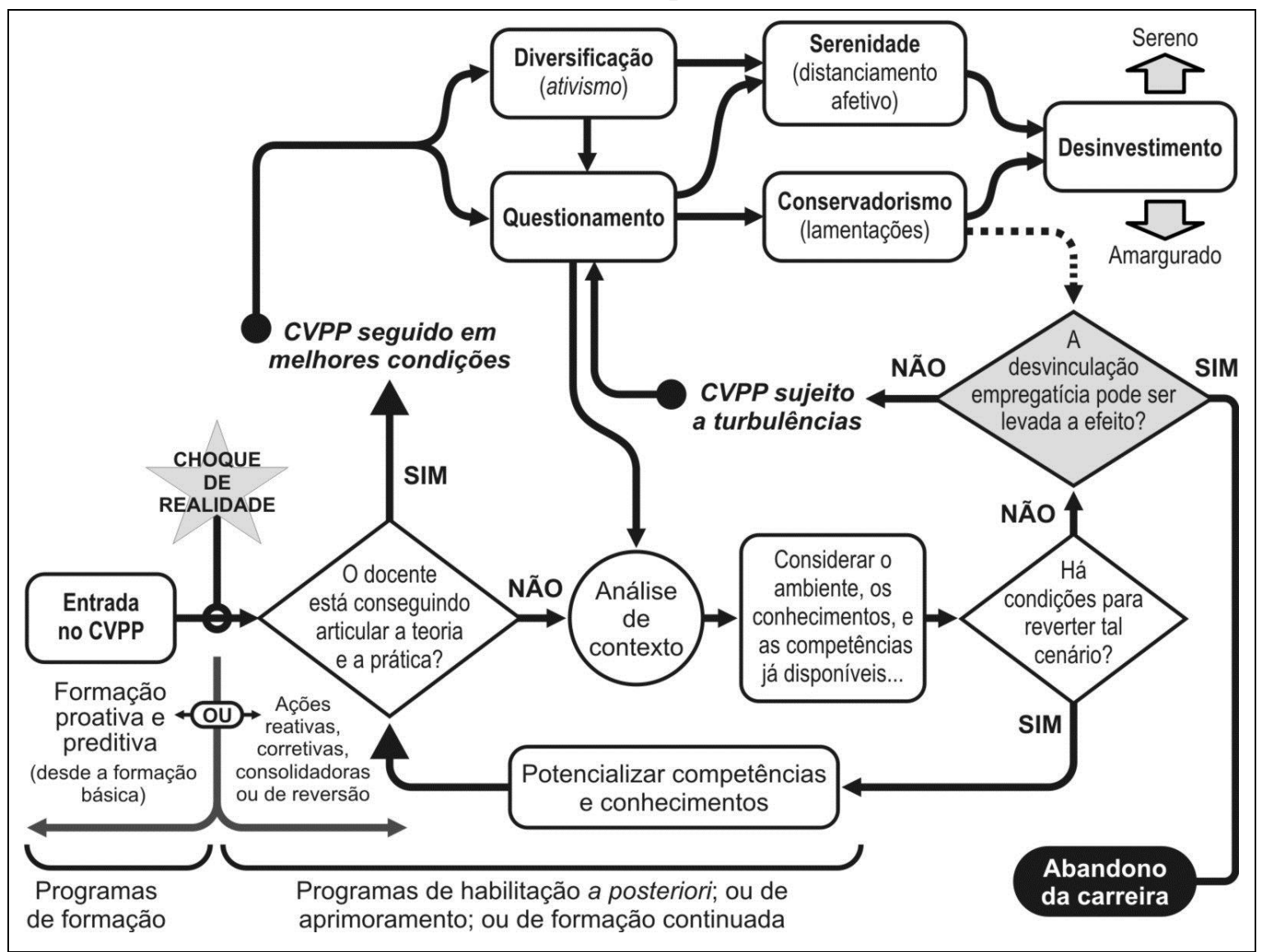

Fonte: Elaboração baseada em Guarnieri (2005), combinado com Huberman (1992) e Veenman (1984), apud Marcelo (1991 e 1998).

Antes de comentar sobre o fluxograma da Figura 2 em tela, deve-se retomar o iconográfico da Figura 1 anterior, no qual se verifica que, além de diversas formas de percurso que poderiam ser seguidas pelos professores, a possibilidade de abandono de carreira foi considerada praticamente em todas as etapas da trajetória do CVPP, apesar de os respectivos autores postularem uma suposta maior probabilidade de ocorrência nas fases incipientes.

Já no fluxograma da agora Figura 2, a questão do abandono da carreira é colocada de forma pragmática, na intenção de demonstrar mais especificamente os distintos momentos e contextos em que tal abandono poderia ser considerado, subsequente à possibilidade de uma desvinculação empregatícia. No que, obviamente, estariam implícitos os efeitos legais decorrentes do estatuto da estabilidade, nas mais diversas implicações ao longo do CVPP.

Considerar uma maior probabilidade de abandono de carreira logo nas etapas iniciais se justificaria a partir do momento em que se entenda que, quanto mais se 
avança no percurso do CVPP, menores serão os ânimos e a coragem do professor para buscar outra forma de sobrevivência, sobretudo se a estabilidade empregatícia já tiver sido adquirida. Por haver certo senso comum sobre ser mais fácil um iniciante buscar um novo caminho profissional do que aquele que já cumpriu boa parte do CVPP, talvez seja a razão de menores preocupações envolvendo a entrada na carreira da docência, e mais ações focadas em outras etapas. Ou seja, uma suposta tentativa de adequar um quadro docente já consolidado.

Tanto os programas intempestivos de formação (habilitação a posteriori), quanto os de formação continuada ou de aprimoramentos contínuos à docência, se fazem legítimos e até essenciais para qualquer política docente. Contudo, há se considerar o nível de sinergia na dinâmica educacional brasileira que decorra de tais iniciativas, proporcionado pelos próprios docentes da rede pública de ensino. Nesse enredo, e evitando qualquer generalização, seria oportuno distinguir os profissionais da Educação que seriam motivados apenas por razões pecuniárias - no caso de ao menos se dispuserem a participar de tais programas - daqueles que primam pela essência da missão educacional, independentemente de outras questões.

Por essa leitura, aguça-se certa percepção do que poderia ser um deslocamento das relações sociais de contextos locais de interação, e sua reestruturação por meio de extensões indefinidas de tempo-espaço como premissas de um desencaixe, pelo qual seria possível melhor capturar os alinhamentos em mudança de tempo e espaço, fundamentais para a mudança social em geral e para a natureza da modernidade em particular $^{5}$. Restaria, contudo, definir dois pontos: 1) o que seria a modernidade para o contexto educacional brasileiro; e 2) qual seria a necessidade, importância e/ou disposição de ajustes frente a tal modernidade.

Independentemente de quaisquer posicionamentos ideológicos, que eventualmente poderiam ou não ter relevância na presente discussão, considera-se aqui que a acirrada competitividade entre as nações, no atual mundo globalizado, é uma realidade. Assim sendo, se os dois pontos citados apontarem para a premência de um eventual desencaixe na Educação Brasileira, cabe tratar essa questão com a devida isenção. E mais, deve-se procurar enxergá-la além dos espectros dimensionais a que estamos atrelados, de modo a expandir o entendimento a toda a complexidade que envolve a dinâmica educacional. No intuito de evitar que o campo de visão fique

${ }^{5}$ Cf. Giddens (1991, p.24). 
meramente restrito a uma vivência cotidiana que retenha seu colorido e espontaneidade apenas no perímetro da gaiola de "aço rígido" da racionalidade burocrática ${ }^{6}$.

Destarte, ao analisar atentamente a Figura 2, haveria a possibilidade de considerar que a docência possa estar sendo colocada no centro do universo educacional de forma a comprometer sobremaneira aqueles que, em tese, deveriam ocupar tal posição: os alunos.

Considerar a possibilidade de os discentes, da rede pública de ensino, incorrerem no risco de ficarem sujeitos a uma parcela de professores "blindados" pela estabilidade, mas sem vocação e/ou qualquer identidade com a missão educacional, que ademais carregam amarguras e decepções e cujo CVPP está sendo em meio a turbulências incontornáveis, e não ser possível agir de modo a reverter essa situação por conta de o sistema educacional estar aprisionado numa gaiola anódina de rotina burocrática-legal seria, no mínimo, afrontar a essência do utilitarismo; ou, em última instância, vilipendiar o futuro de toda uma nação.

Se a estabilidade, como ficha simbólica, já conseguiu assegurar para si a confiança por parte da sociedade - a qual reconhece e honra o valor de tal estatuto -, falta garantir que a docência e o CVPP se consolidem como sistema perito, sobretudo quanto à contrapartida de confiança, em reciprocidade, esperada e até exigida nesse sentido. Para desse modo a Educação Pública do Brasil se desencaixar, tendo plenas condições para decolar ao compasso do que se entenderia por modernidade; se assim de fato a sociedade como um todo desejar.

Nesse enredo volitivo, restaria decidir se o universo da Educação Pública Brasileira seria afinal regido por um "docentrismo" ou por um "discentrismo" (em alusão ao embate entre o geocentrismo e o heliocentrismo que perdurou por séculos). Ou, em um contexto mais programático em detrimento de um puramente pragmático, que ao menos sejam consideradas as formas que permitam vencer o desafio em conciliar (contemporizar) um eventual impasse nesse sentido.

\footnotetext{
REFLECTIONS ON A DISEMBEDDING IN BRAZILIAN EDUCATION AND THE EVENTUAL IMPASSE BETWEEN TEACHERCENTRISM AND STUDENTCENTRISM
}

${ }^{6}$ Cf. Weber (apud GIDDENS, 1991, p.123). 
ABSTRACT: Undocked institutions widely dilate the scope of time-space distancing, since the separation between these elements is crucial for the extreme dynamism of modernity. This separation is the prime condition of the process of disembedding, in which the displacement of social relations of local contexts of interaction and its redesign through indefinite extensions of time and space are favored. Therefore, there are two types of dislocated mechanisms intrinsically involved in the development of social modern institutions: symbolic tokens and expert systems. These mechanisms depend on reliability. Within this context, this present paper sees the professional life cycle of the teacher in the perspective of the expert system. It also sees the work stability of public servants in the symbolic token perspective, more specifically public teachers in Brazil. This paper also attempts to propose some reflections on what a disembedding in Brazilian education would mean and on how an eventual impasse between teachercentrism and studentcentrism would affect this process if necessary or desired, from one would understand by modernity.

KEYWORDS: Disembedding. Expert systems. Symbolic tokens. Professional Life Cycle of the Teacher. Work stability.

\section{REFERÊNCIAS}

BURKE, P. Teacher development. London: Falmer Press, 1988.

BURKE, P. et al. Teacher career stages: implications for staff development. Bloomington: Phi Delta Kappa Educational Foundation, 1984.

FULLER, F.; BROWN, D. Bwming a teacher. In: RYAN, K. (Ed.). Teacher Education. Chicago: NSSE, 1975. p.25-52.

GATTI, B. A.; BARRETO, E. S. de S.; ANDRÉ, M. E. D. de A. Políticas docentes no Brasil: um estado da arte. Brasília: UNESCO, 2011. Disponível em:

<http://unesdoc.unesco.org/images/0021/002121/212183por.pdf〉. Acesso: 06 ago.12.

GIDDENS, A. As consequências da modernidade. Tradução Raul Fiker. São Paulo: Ed. UNESP, 1991. Disponível em: <www.afoiceeomartelo.com.br〉. Acesso: 03 jul.13.

GUARNIERI, M. R. O início da carreira docente: pistas para o estudo do trabalho do professor. In: GUARNIERI, M. R. (Org.). Aprendendo a ensinar: o caminho nada suave da docência. 2.ed. Campinas: Autores Associados, 2005. p.5-23.

HUBERMAN, M. O ciclo de vida profissional dos professores. In: NÓVOA, A. (Org.). Vida de professores. Porto: Porto Ed., 1992. p.141-169.

The professional life cycle of teachers. Teacher College Records, New York, v.91, n.1, p.31-57, 1989.

MARCELO, C. Pesquisa sobre formação de professores: o conhecimento sobre o aprender a ensinar. Tradução: Lólio Lourenço de Oliveira. Revista Brasileira de Educação, São Paulo, n.9, p.51-75, 1998.

Aprender a enseñar: un estudio sobre el proceso de socialización de profesores principiantes. Madrid: Centro de Publicaciones del Ministerio de Educación y Ciencia: C.I.D.E., 1991. 
PETERSON, W. A. Age, teacher's role and the institutional setting. In: BIDDLE, B.; ELLENA, W. (Ed.). Contemporary research on teacher effectiveness. New York: Holt, Rinehart \& Winston, 1964. p.264-277.

VEENMAN, S. Perceived problems of beginning teachers. Review of Educational Research, Washington, v.54, n.2, p.143-178, 1984. 